\title{
An Integrated Assessment Model for Evaluating Air Pollution Mitigation Policy
}

\author{
$\mathrm{Na} \mathrm{LI}{ }^{\mathrm{a}, \mathrm{b}, 1}$ \\ a School of Economics and Management, University of Chinese Academy of Sciences, \\ Beijing, China \\ ${ }^{\mathrm{b}}$ Research Center on Fictitious Economy and Data Science, Chinese Academy of \\ Sciences, Beijing, China
}

\begin{abstract}
Comprehensive evaluation of anti-policies to tackle the severe haze problem is of great scientific significance to the improvement of air quality. In this study, an integrated assessment model of air pollution control is built, based on submodels of multi-regional CGE model, GAINS model and health effect model. It models the links of economic, environmental and health, and considers feedback effects among them. Then, this paper takes the Jing-Jin-Ji region as an example, integrating the regional economic, energy and environmental data and air pollution mitigation policies, and explain how to make a cost-benefit analysis of air pollution prevention and control for this region. The model can be applied for other regions in the comprehensive evaluation of air pollution control policies.
\end{abstract}

Keywords. Integrated assessment model, air pollution, mitigation policy.

\section{Introduction}

Air pollution has attracted more and more attention from governments and the public worldwide. Different scholars have studied the health loss caused by air pollution and $\mathrm{PM}_{2.5}$ from different spatial scales [1]-[3]. To control air pollution, governments have implemented many mitigation policies. It is very necessary to systematically quantify the costs and benefits of these policies and then conduct cost-benefit analysis (CBA), which will be an important reference for future policy improvement. Estimating the environmental impact of air quality improvement (or emission reduction) and their economic impact are two particularly important aspects of cost-benefit analysis.

In assessing the economic impact of air policies, computable general equilibrium (CGE) models, as well as hybrid models based on CGE and bottom-up methods, have been increasingly widely used. These studies mainly analyze the impact of air pollution mitigation on macroeconomic changes and emission reduction effects [4]-[6]. In terms of evaluating the environmental and health impacts of air policies, many scholars have studied the environmental effects and their impacts on $\mathrm{PM}_{2.5}$ pollution control targets [7][8], as well as the benefits of health improvement caused by these air pollution control policies [9]-[10]. The environment and the economy are interconnected organisms, so environmental impacts also affect the economy and vice versa. However, these studies

\footnotetext{
${ }^{1}$ Corresponding Author, Na LI, University of Chinese Academy of Sciences, Beijing, China; E-mail: lina@ucas.ac.cn.
} 
tend to study environmental and economic impacts as independent aspects, and only a few research have evaluated the effect of air pollution mitigation polices on the health feedback to the economy as a whole [11].

Therefore, the previous assessment studies of air pollution control policies more biased toward one or two aspects (economic, environmental or health), and focus less on the comprehensive evaluation research [12], especially modeling the links of economic, environmental and health, and considering feedback effects among them. Then, few researchers have been able to systematically analyze the cost-effectiveness of air pollution regulation policies. In addition, most existing studies do not consider the costs of direct implementation of specific air policies. The direct emission reduction expenditures of different emission reduction technologies (or equipment or measures) are not the same, and these expenditures also produce the increase in the demands of other sectors' goods, which will bring an important pulling effect on the whole economic system.

To make up for the shortcomings of the above research, this research builds a comprehensive evaluation model of air pollution embedded a Chinese regional economy - energy - environmental CGE model, a Greenhouse Gas-Air Pollution Interactions and Synergies (GAINS) model and a health effect model and the feedback relationship between them. Next, this paper takes the Jing-Jin-Ji region as an example to explain how to make a cost-benefit analysis of air pollution prevention and control for this region.

\section{The Integrated Assessment Model}

The comprehensive assessment model of air pollution constructed in this paper includes three main models: a China's multi-regional economy-energy-environment CGE model, an air quality model based on GAINS model and a health effect model. By soft-link with the three models, taking into account the linkages and feedback among them, the integrated assessment model can provide valuations of relevant policies from the interdisciplinary perspectives. (figure 1).

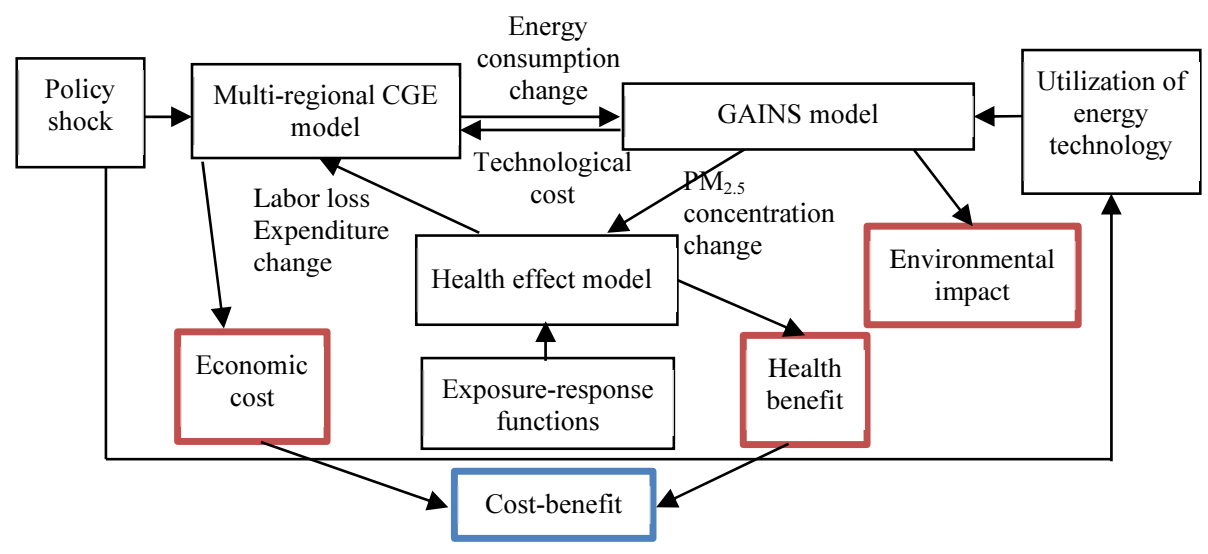

Figure 1. Basic framework of integrated assessment model for air pollution 


\subsection{China's Multi-Regional Cge Model}

The model includes 30 provincial regions-consisting of Hebei, Beijing, Tianjin and other regions, 17 production departments, 3 kinds of primary factors for production (labor, capital and energy) and 4 kinds of emissions (primary PM2.5, NOx, SO2 and VOCs). In the model, to decide separately the supply or demand of goods and primary factors, the agents in the market maximize their objective functions, such as enterprises maximize profit, and households and governments maximize their utilities respectively. The model is recursively dynamic and by capital accumulation, labor force changes and technology improvements, the development of regional economic is realized over time. For model details, please refer to Li et al. (2019) [13].

The abatement expenditure cost and resulting direct reduction of related pollutant emissions are calculated and embedded into the model for the specific measures of air pollution control, e.g. end-of-pipe treatment, mitigation from transportation vehicles, and VOC reduction. We model the abatement expenditure per sector as an additional intermediate input to be added to the unit production cost. This can generate additional product demands of some industries, such as mechanical and electronic manufacturing, chemical and construction industries, for emission reduction devices, mitigation technologies, or other expenditure. The using of mitigation devices and technologies can also reduce the polluted emissions directly by lowering the corresponding emission factors. In addition, for some structural adjustment measures, e.g. coal consumption reduction and production capacity reduction, the emission reduction cost is imposed to the model in the form of constructing implicit tax under the corresponding policy constraint.

\subsection{The Air Quality Model Based on Gains Model}

GAINS is a widely used authoritative model for evaluating policies that aim to mitigate emissions of multiple air pollutants and greenhouse gases at the lowest costs, and decrease their adverse influences on human health, ecosystems and climate change to minimum, containing the energy consumption structure of different departments and sources and hundreds of different energy technology information (https://gains.iiasa.ac.at/models/gains_models4.html). Based on the GAINS-China model, we calculate the resulting structures of energy consumption and energy technology utilization for Chinese different regions, sectors and technical equipment caused by specified packages of measures, and input them into the model, to make it applicable for the analysis of China air pollution control. Then, the model can calculate resulting effects on ambient air quality, including $\mathrm{PM}_{2.5}$ concentration.

\subsection{The Health Effect Model}

In this model, we use the exposure-response functions developed by Xie et al. (2016)[14] (equation 1 and 2). A China-specific linear function is built for $\mathrm{PM}_{2.5}$-related morbidity. The number of health endpoints $E P$ is estimated by multiplying population and reported cause-specific mortality rate with the population attributable fraction, which is 1 minus the inverse of the relative risk $(R R)$. 


$$
\begin{gathered}
R R_{r, y, t, g}(C)=\left\{\begin{array}{c}
1, \text { if } C_{r, y} \leq C 0 \\
1+C F_{t, g}\left(C_{r, y}-C 0\right), \text { if } C_{r, y} \geq C 0 \text { linear function } \\
1+\beta \times e^{\left(-\gamma \times\left(C_{l a, l o, y}-C 0\right)^{\sigma}\right)}, \text { if } C_{r, y} \geq C 0 \text { nonlinear function }
\end{array}\right. \\
E P_{r, y, t, g}(C)=\left\{\begin{array}{c}
P_{l a, l o, y} \times\left(R R_{r, y, t, g}(C)-1\right) \text { linear morbidity function } \\
P_{l a, l o, y} \times\left(R R_{r, y, t, g}(C)-1\right) \times I_{l a, l o, t} \text { linear mortality function } \\
P_{l a, l o, y} \times \frac{R R_{r, y, t, g}(C)-1}{R R_{r, y, t, g}(C)} \times I_{l a, l o, t} \text { nonlinear mortality function }
\end{array}\right.
\end{gathered}
$$

Where $R R(C)$ represents the relative risk of every endpoint per year; $C$ means the pollutant concentration level; $C O$ is the concentration threshold causing health damage; $C R$ is the linear concentration-response function; $\beta, \gamma, \sigma$ are the parameters of nonlinear concentration-response function; EP stands for the health endpoint per year; $P$ stands for population, aged 15-65 for work loss day, age 25-65 for stroke and ischemic heart disease, and entire cohort for other endpoints; $I_{l a, l o, t}$ represents the average natural death rate per year for each endpoint; Subscript $r, y, t, g$, la, lo means region, year, endpoint, value range (low, medium and high), latitude, longitude, respectively.

In this study, the labor loss can be obtained by calculating the total work loss day. That is the sum of cumulative loss of work days from morbidity and chronic mortality caused by pollution. And then, we can obtain the additional health expenditure based on the product of total endpoints and the expenses of hospital admission and outpatient for each endpoint. Last, we calculate the value of health endpoint (VE) according to the willingness to pay (WTP) method, in which we use a per capita GDP index to estimate the value of statistical life (equation 3 ).

$$
V E_{l a, l o, y, t}=E P_{l a, l o, y, t} \times W T P_{l a, l o, y, t} \times\left(\frac{P G D P_{l a, l o, y}}{P G D P_{2010}}\right)^{0.5}
$$

\subsection{The Linkages of Sub-Models}

There are some linkages and feedbacks among these sub-models. First, the change of energy consumption simulated by the multi-regional CGE model, is put into the air quality model with the energy technological improvement caused by the policy to simulate the $\mathrm{PM}_{2.5}$ concentration. Then, the changed $\mathrm{PM}_{2.5}$ concentration is taken into the health effect model to simulate the change of the health damage. Next, the resulting labor loss and medical expenditure from the health effect model, and the technological cost from the air quality model are all input into the CGE model to simulate it again, to obtain the final economic cost. The final economic cost from the CGE model and the health benefit from the health effect model are used for the CBA analysis.

\section{The Cba Analysis for Jing-Jin-Ji Region}

The Jing-Jin-Ji area is located in the North of China, including two metropolitans (Beijing (Jing), the capital of China, and Tianjin (Jin)) and a province-Hebei (Ji). This area has the most serious air pollution in China due to lots of coal consumption and burning, especially in winter. In order to change this situation and solve this acute air 
polluted problem in this area, "Air Pollution Prevention and Control Action Plan" and its enhanced measures in this area have been carried out by the Chinese central government. A lot of specific mitigation policies and required emission reduction targets are regulated. Thus, we take the Jing-Jin-Ji region as an example, integrating the regional economic, energy and environmental data and air pollution mitigation policies, to build a cost-benefit evaluation approach of air pollution prevention and control policies.

\subsection{Model Data}

The main economic data used in the model is China's inter-regional input-output table in 2012. The environmental and energy data used are from China energy statistical yearbook and Tsinghua University's MEIC (multi-resolution emission inventory for China) database. The direct reduction data, and the data of direct abatement expenditure costs for related policies (table 1) are estimated according to the air policy plans, literature study and statistical data. TFP is obtained by calibrating based on GDP growth. In baseline, we set GDP growth derived from the "2007-2012" historical records and the economic development goals of local government in the "12th Five-year plans" and "13th Five-year plans".

In order to build the Jing-Jin-Ji air quality model based on Gains model, we revise the possible changes in energy consumption and energy technology (such as changes in penetration rate) under different specific policies (or different scenarios) for air pollution control, referring to the research of d He et al. (2014) [9], Wu et al. (2017) [15] and Liu et al. (2019) [16].

Table 1. The expenditure costs of direct abatement for the Action Plan and Enhanced policies (100 million Yuan)

\begin{tabular}{|c|c|c|c|c|}
\hline Policies & Sectors & $\begin{array}{c}\text { Beijin } \\
\mathbf{g}\end{array}$ & $\begin{array}{c}\text { Tianji } \\
\mathbf{n}\end{array}$ & Hebei \\
\hline Structure adjustment & Industry & 212.33 & 95.24 & $\begin{array}{c}380.9 \\
5\end{array}$ \\
\hline \multirow{4}{*}{ End-of-pipe treatment } & Power and heat supply & 3.21 & 125.57 & $\begin{array}{c}540.6 \\
4\end{array}$ \\
\hline & Industry sector & 27.42 & 33.04 & $\begin{array}{c}102.0 \\
2\end{array}$ \\
\hline & Metals smelting and pressing-steel & 0 & 12.35 & 89.28 \\
\hline & $\begin{array}{l}\text { Non-metallic mineral products manufacturing- } \\
\text { cement }\end{array}$ & 0.13 & 0.08 & 1.43 \\
\hline $\begin{array}{c}\text { Reductions from } \\
\text { vehicles }\end{array}$ & Transportation & 185.23 & 41.24 & $\begin{array}{c}151.4 \\
2 \\
\end{array}$ \\
\hline VOC reduction & Petrochemical Industry & 27.69 & 42.11 & 22.96 \\
\hline
\end{tabular}

Source: calculated based on Air Pollution Prevention and Control Action Plan, Enhanced measures of Air Pollution Prevention and Control in Beijing-Tianjin-Hebei area and He et al. (2014).

\subsection{The Cba Analysis Approach}

The total cost of air pollution control consists of the direct abatement cost and indirect economy-wide cost. The latter one includes the impacts of the labor loss, the additional health expenditure and the direct technological abatement cost on the whole economy. By running the integrated model in which the CGE model need to be run twice, we can obtain the total cost $(T C)$. Health benefit $(H B)$ mainly comes from the value saving of 
health endpoint from the health effect model. The ratio of benefit and cost $(R B T)$ can be calculated by equation 4 .

$$
R B T_{r}=\frac{H B_{r}}{T C_{r}}
$$

\section{Conclusion}

This paper develops a comprehensive evaluation model of air pollution control, embedded three sub-models of multi-regional CGE model, GAINS model and health effect model, and feedbacks between them. Taking the Jing-Jin-Ji region as an example, we build a cost-benefit assessment approach of air pollution prevention and control policies. This approach can be applied for other regions in the comprehensive evaluation of air policy.

\section{Acknowledgment}

This study was supported by the National Natural Science Foundation of China (No. $71673262)$

\section{References}

[1] Chen YY, Ebenstein A, Greenstone M, Li HB. Evidence on the impact of sustained exposure to air pollution on life expectancy from China's Huai River policy. PNAS, 2013, 110: 12936-12941.

[2] Li G, Fang C, He S. The influence of environmental efficiency on PM2.5 pollution: Evidence from 283 Chinese prefecture-level cities. Science Of The Total Environment, 2020, 748: 141549.

[3] Gupta A, Bherwani H, Gautam S, Anjum S, Musugu K, Kumar N, Kumar R. Air pollution aggravating covid-19 lethality? exploration in asian cities using statistical models. Environment Development And Sustainability, 2021, 23: 6408-6417.

[4] Chen SM, He YL. Welfare loss of China's air pollution: How to make personal vehicle transportation policy. China Econ. Rev., 2014, 31: 106-118.

[5] Vrontisi Z, Abrell J, Neuwahl F, Saveyn B, Wagner F. Economic impacts of EU clean air policies assessed in a CGE framework. Environ. Sci. Policy, 2016, 55: 54-64.

[6] Ma J, Li ZG. Economic policy of PM2.5 mitigation. China Economy Press: Beijing. 2014.

[7] He K, Zhang Q, Hong CP, Xie HX, Bai Y, Du J, Zhao LJ, Cai JJ, Lin Y, Zhou R. Can Beijing, Tianjin and Hebei Achieve Their PM2.5 Targets by 2017? Assessment of the potential for air quality improvements in the Beijing-Tianjin-Hebei region under China's new air pollution action plan Beijing-Tianjin-Hebei. AQM Policy Report Series, 2014.

[8] Jiang XJ, Hong CP, Zheng YX, Zheng B, Guan DB, Gouldson A, Zhang Q, He KB. To what extent can China's near-term air pollution control policy protect air quality and human health? A case study of the Pearl River Delta region. Environ. Res. Lett., 2015, 10: 104006.

[9] Xie Y, Dai HC, Zhang YX, Wu YZ, Hanaoka T, Masui T. Comparison of health and economic impacts of PM2.5 and ozone pollution in China. Environment International, 2019, 130: 104881.

[10] Zhang X, Jin Y, Da H, Xie Y, Zhang S. Health and economic benefits of cleaner residential heating in the Beijing-Tianjin-Hebei region in China. Energy Policy, 2019, 127: 165-178.

[11] Nam K M, Selin N E, Reilly J M and Paltsev S 2010. Measuring welfare loss caused by air pollution in Europe: A CGE analysis Energy Policy 38 5059-5071

[12] Zhang J, Jiang H Q, Zhang W et al. Cost-benefit analysis of China's Action Plan for Air Pollution Prevention and Control. Front. Eng., 2019, 6: 524-537.

[13] Li N, Zhang X L, Shi M J, Hewings GJD. Does China's air pollution abatement policy matter? An assessment of the Beijing-Tianjin-Hebei region based on a multi-regional CGE model. Energy Policy, 2019, 127: 213-227. 
[14] Xie Y, Dai H, Dong H, Hanaoka T, Masui T. Economic impacts from PM2.5 pollution-related health effects in China: A provincial-level analysis Environmental Science \& Technology. 2016, 50: 4836-4843.

[15] Liu C, Dai H, Zhang L, Feng C. The impacts of economic restructuring and technology upgrade on air quality and human health in Beijing-Tianjin-Hebei region in China. Frontiers of Environmental Science and Engineering, 2019, 13: 70.

[16] Wu R, Dai H, Yong G, Xie Y, Masui T, Liu Z, Qian Y. Economic Impacts from PM2.5 Pollution-Related Health Effect: A Case Study in Shanghai. Environmental Science \& Technology, 2017, 51: 5035-5042. 